\title{
IDENTIFIKASI PENANGANAN KEHAMILAN SEROTINUS DI RSUD DR. H SOEWONDO KENDAL
}

\author{
Tri Nurhidayati ${ }^{1}$, Budi Astyandini ${ }^{2}$, Sri Setiasih ${ }^{3}$ \\ 1,2,3UPP Kampus Kendal Poltekkes Kemenkes Semarang
}

\begin{abstract}
ABSTRAK
Kehamilan umumnya berlangsung 40 minggu atau 280 hari dihitung dari hari pertama haid terakhir (HPHT). Namun, sekitar 3,4-14\% atau rata-rata 10\% kehamilan berlangsung sampai 42 minggu atau lebih.Kehamilan lewat waktu merupakan salah satu kehamilan resiko tinggi.Hal ini berhubungan erat dengan mortalitas, morbiditas perinatal, ataupun makrosomia.Adapun penyebab kematian perinatal adalah kelainan kongenital, prematuritas, trauma persalinan, infeksi, gawat janin dan asfiksia neonatorum.Terjadinya gawat janin disebabkan oleh induksi persalinan, infeksi pada ibu, perdarahan, insufisiensi plasenta, prolapsus tali pusat, kehamilan dan persalinan preterm dan postterm. Untuk mengetahui seberapa besar upaya tenaga kesehatan dalam memberikan pelayanan, Tujuan penelitian ini adalah untuk mengidentifikasi penanganan kehamilan serotinus di RSUD Dr.H.Soewondo Kabupaten Kendal.Desain yang digunakan adalah deskriptif yaitu suatu desain yang dilakukan terhadap sekumpulan objek yang bertujuan unuk melihat gambaran fenomena (termasuk kesehatan) yang terjadi disuatu populasi tertentuserta metode yang digunakan adalah dengan melihat data ibu bersalin serotinus dengan penanganannya yang tertera di Rekam Medis. Populasi dalam penelitian ini adalah ibu bersalin kehamilan serotinussebanyak 108 responden.Sampel dalam penelitian ini menggunakan sampel jenuh.

Menunjukkan bahwa dari 108 ibu bersalin dalam penanganannya adalah 22 (20,4\%) dengan metode menunggu, 11 (10,2\%) dengan induksi persalinan, 75 (69,4\%) dengan seksio sesarea. Kesimpulannya sebagian besar responden (ibu bersalin) dalam penanganannya menggunakan metode seksio sesarea.Bagi ibu hamil disarankan untuk segera datang ke rumah sakit untuk mendapat penanganan secara optimal.
\end{abstract}

Kata Kunci : Penanganan, Serotinus 


\section{PENDAHULUAN}

\section{A. Latar Belakang}

Kehamilan

umumnya

berlangsung 40 minggu atau 280 hari

dihitung dari hari pertama haid terakhir (HPHT). Kehamilan aterm ialah usia

kehamilan antara 38-42 minggu dan ini merupakan periode terjadinya persalinan normal. Namun, sekitar 3,4$14 \%$ atau rata-rata $10 \%$ kehamilan

Kehamilan postterm disebut juga kehamilan serotinus, kehamilan lewat waktu, kehamilan lewat bulan, prolonged pregnancy, extended pregnancy, post date/pos datisme atau pascamaturitas adalah kehamilan yang berlangsung sampai 42 minggu (294 hari) atau lebih, dihitung dari haid terakhir (HPHT) dengan siklus haid rata-rata 28 hari. $^{(1,2)}$

Kriteria untuk kehamilan lewat waktu dipenuhi bila persalinan tidak terjadi dalam dua minggu setelah taksiran persalinan ditentukan. Beberapa ahli dapat menyatakan kehamilan lewat waktu bila lebih dari berlangsung sampai 42 minggu atau lebih. Kehamilan lewat waktu merupakan salah satu kehamilan resiko tinggi.Hal ini berhubungan erat dengan mortalitas, morbiditas perinatal, ataupun makrosomia. Resikobagi ibu dengan kehamilan postterm dapat berupa perdarahan pascapersalinan ataupun tindakan obstetrik yang meningkat. ${ }^{(1)}$

41 minggu karena angka morbiditas dan mortalitas neonatus meningkat setelah usia 40 minggu. Namun kurang lebih 18\% kehamilan akan berlanjut melebihi 41 minggu hingga 7\% akan menjadi 42 minggu bergantung pada populasi dan kriteria yang digunakan untuk menghitung usia kehamilan. ${ }^{(3)}$

Angka kematian bayi (AKB) di Indonesia pada tahun 2007 2-5 kali lebih tinggi mencapai 34 per 1000 kelahiran hidup atau 2 kali lebih besar dari target WHO yaitu sebesar $15 \%$ per kelahiran hidup. $^{(4)}$ Adapun penyebab kematian perinatal adalah 
kelainan kongenital, prematuritas, trauma persalinan, infeksi, gawat janin dan asfiksia neonatorum. Terjadinya gawat janin disebabkan oleh induksi persalinan, infeksi pada ibu, perdarahan, insufisiensi plasenta, prolapsus tali pusat, kehamilan dan persalinan preterm dan postterm. Persalinan postterm menunjukkan bahwa kehamilan telah melampaui waktu perkiraan persalinan menurut hari pertama menstruasinya. Sedangkan AKB di Jawa Tengah pada tahun 2010 berjumlah 10,62/1000 kelahiran hidup. Di Kendal AKB pada tahun yang sama, sebanyak $7,3 / 1000$ kelahiran hidup. Pada tahun 2011 dari bulan Januari sampai dengan bulan November AKB di Kendal sebanyak $7,1 / 1000$ kelahiran hidup. ${ }^{(5)}$

Pada survey pendahuluan yang dilakukan pada ibu bersalin di RSUD dr.H.Soewondo Kendal berdasarkan data dari tanggal 3 Maret 2013 terdapat 34 persalinan serotinus. Dari jumlah kehamilan serotinus, terdapat 5 $(14,7 \%)$ persalinan serotinus dengan metode menunggu, $20 \quad(58,8 \%)$ dengan induksi persalinan dan 9 $(26,5 \%)$ dengan ceksio cesarea.

Berdasarkan uraian diatas penulis tertarik untuk melakukan penelitian yang berjudul "Identifikasi penanganan kehamilan serotinus di RSUD dr.H.Soewondo Kendal".

\section{B. Tujuan Penelitian}

Untuk mengidentifikasi penanganan kehamilan serotinus di RSUD Dr.H.Soewondo Kabupaten Kendal.

\section{METODE PENELITIAN}

Kerangka konsep atau kerangka berfikir merupakan dasar pemikiran pada penelitian yang dirumuskan dari fakta, observasi dan tinjauan pustaka. ${ }^{(14)}$

Desain penelitian dalam penelitian ini adalah desain deskriptif. Pada penelitian ini menggambarkan tentang penanganan kehamilan serotinus, sedangkan metode yang digunakan adalah dengan melihat data ibu bersalin hamil serotinus dengan penanganannya yang tertera di buku register. Dalam penelitian ini peneliti menggunakan variabel tunggal yaitu variabel yang berdiri sendiri, tidak ada 
variabel lain yang mendampingi. ${ }^{(16)}$ Variabel dalam penelitian ini adalah penanganan kehamilan serotinus.

Populasi merupakan keseluruhan objek penelitian. ${ }^{(15)}$

Populasi dalam penelitian ini adalah seluruh ibu hamil serotinus (kehamilan lewat bulan) di RSUD Dr.H.Soewondo Kendal dari bulan Januari sampai dengan bulan Mei 2013 sebanyak 108 responden. Sampel adalah sebagian atau wakil populasi yang diteliti. ${ }^{(17)}$ Sampel dalam penelitian ini menggunakan sampel jenuh yaitu dengan mengambil semua anggota populasi.(18) Sampel dalam penelitian ini adalah seluruh ibu hamil serotinus (kehamilan lewat bulan) di RSUD Dr.H.Soewondo Kendal dari bulan Januari sampai dengan bulan Mei 2013 sebanyak 108 responden.

Instrumen penelitian adalah alat atau fasilitas yang digunakan peneliti dalam mengumpulkan data sehingga mudah untuk diolah.Instrumen yang digunakan dalam penelitian ini adalah dokumentasi yang berisi tentang kehamilan serotinus beserta penanganannya yang diambil dari data RSUD Dr.H.Soewondo Kendal.
Metode dokumentasi yang digunakan dapat dilaksanakan dengan Check List yaitu daftar variabel yang akan dikumpulkan datanya dan memberikan tanda atau tally setiap pemunculan gejala yang dimaksud. ${ }^{(17)}$

Pengolahan data meliputi Editing( pemeriksaan data ) adalah memeriksa daftar pertanyaan yang telah diserahkan oleh para pengumpul data.Tujuannya adalah mengurangi kesalahan atau kekurangan yang ada di daftar pertanyaan. Dalam penelitian ini, setelah data diperoleh, kemudian dilakukan pemeriksaan data dengan cara memeriksa kembali kebenaran data yang diperoleh atau dikumpulkan, dalam hal ini peneliti memilih dan memilah data dari catatan buku register yang berhubungan dengan tujuan penelitian.Data telah diperiksa, dipilih dan dipilah secara benar. Coding( pemberian kode ) adalah mengklasifikasikan jawaban dari para responden ke dalam kategori.Biasanya dalam pemberian kode dibuat juga daftar kode dan artinya dalam satu buku untuk memudahkan kembali melihat lokasi dan arti suatu kode dari suatu variabel. Kode 
dalam penelitian ini menggunakan:

Tabulating( penyusunan daAdalah pekerjaan membuat table.Jawaban jawaban yang telah diberi kode kemudian dimasukkan kedalam tabel. Format tabel terdiri atas dua kolom yaitu no register serta penanganan kehamilan serotinus.

HASIL PENELITIAN DAN PEMBAHASAN

\section{A. Hasil Penelitian \\ A. Hasil}

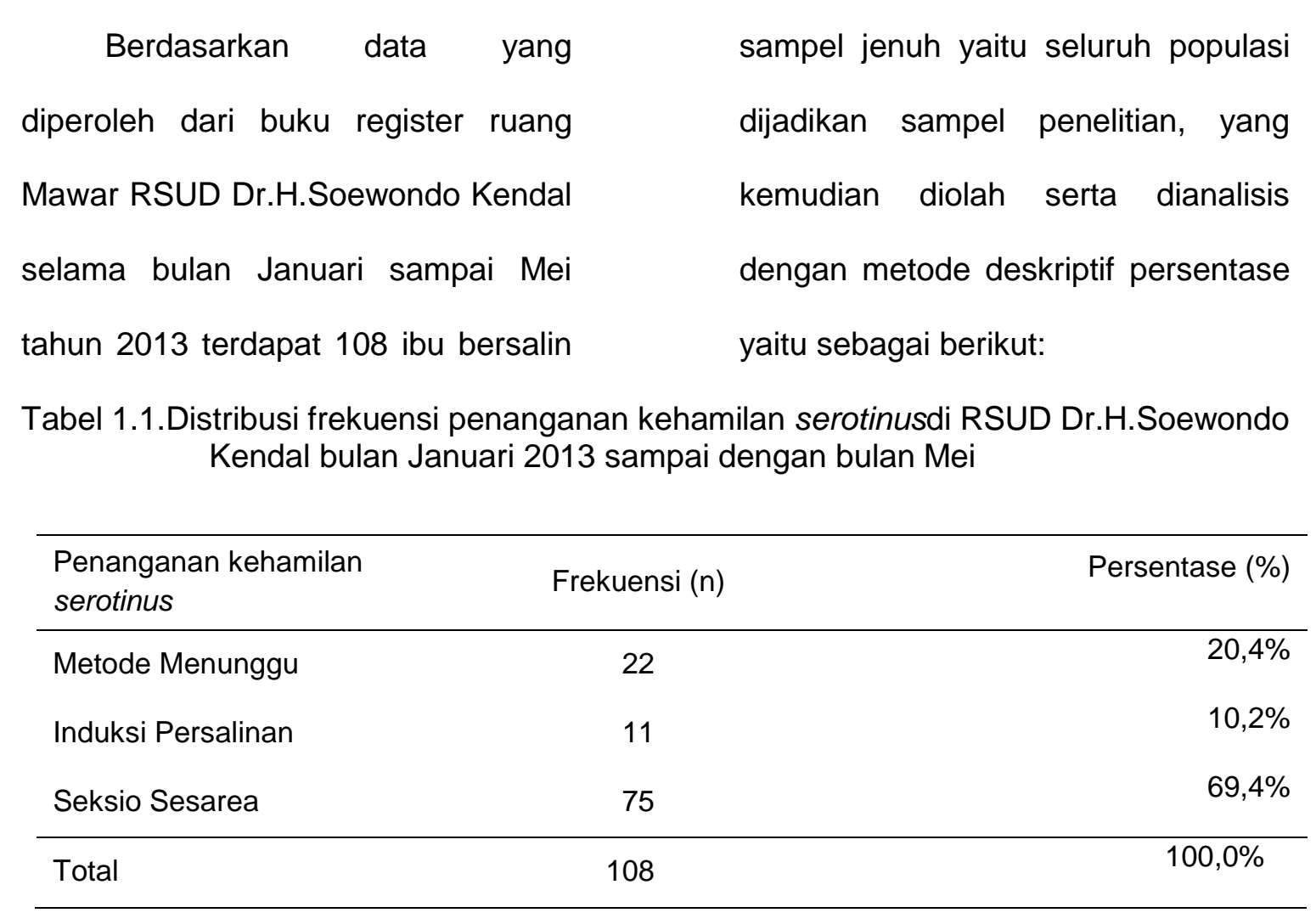

Analisis data yang digunakan dalam penelitian ini adalah analisis univariat.Analisa dilakukan terhadap tiap variabel dari hasil penelitian. Pada umumnya dalam analisis ini hanya menghasilkan distribusi dan persentase dari tiap variabel ${ }^{(15)}$.

dengan kehamilan serotinus. Sampel dalam penelitian ini menggunakan sampel jenuh yaitu seluruh populasi

serta penanganan kehamilan serotinus.
Dari tabel 1.1 sebagian besar penanganan kehamilan serotinus dengan metode seksio sesarea yaitu sebanyak 75 responden $(69,4 \%)$, 
dengan metode menunggu 22 responden ( $20,4 \%)$ dan induksi persalinan 11 responden ( 10,2\%).

\section{B. Pembahasan}

Berdasarkan data yang diperoleh di RSUD Dr.H.Soewondo Kendal sebagian besar penanganan kehamilan serotinus dengan metode seksio sesarea yaitu sebanyak 75 responden (69,4\%), dengan metode menunggu 22 responden ( 20,4\%) dan induksi persalinan 11 responden ( $10,2 \%)$.

Penanganan kehamilan serotinus dengan metode menunggu yaitu mengharapkan proses persalinan spontan tanpa rangsangan dari luar. Harus dilakukan evaluasi kesejahteraan janin dalam uterus dengan berbagai teknik yang adekuat sehingga dapat segera diketahui mulai terjadinya gangguan janin dalam bentuk gawat janin. Gawat janin merupakan indikasi untuk dilakukan terminasi secara induksi atau langsung seksio sesarea. ${ }^{(7)}$ Induksi persalinan adalah suatu tindakan terhadap ibu hamil yang belum inpartu, baik secara mekanik maupun medisinal, guna merangsang timbulnya kontraksi rahim yang merupakan suatu upaya agar persalinan mulai berlangsung baik sebelum atau sesudah umur kehamilan cukup bulan.Sebelum melakukan induksi hendaknya lakukan terlebih dahulu pemeriksaan dalam guna memberikan kesan tentang keadaan serviks, bagian terbawah janin dan panggul (skor bishop).Indikasi dari ibu meliputi penyakit yang diderita, komplikasi kehamilan, serta kondisi fisik.Sedangkan indikasi dari janin yaitu kehamilan lewat waktu, kematian intrauteri, IUGR, kelainan konginetal, ketuban pecah dini.

Kontra indikasi dilaksanakan induksi persalinan ialah terdapat distosia persalinan, terdapat kedudukan ganda, terdapat overdistensi rahim, terdapat perdarahan antepartum, terdapat bekas operasi pada otot rahim, grandemultipara atau kehamilan $>5$ kali, dan terdapat tanda-tanda intrauteri fetal distress. Komplikasi dari induksi persalinan yaitu hiponatremia (kadar natrium darah yang rendah $<136 \mathrm{mEq} / \mathrm{L}$ 
darah), atonia uteri, hiperstimulasi, fetal distress, prolaps tali pusat, solusio plasenta, ruptura uteri, hiperbilirubinemia, perdarahan postpartum, kelelahan ibu dan krisis emosional, serta Infeksi intrauterin. Syarat induksi persalinanmeliputi janin mendekati aterm, tidak terdapat kesempitan panggul atau disproporsi sefalopelvik, memungkinkan untuk lahir per vaginam, dan janin dalam presentasi belakang kepala. ${ }^{(7,11)}$

Seksio sesarea adalah suatu cara melahirkan janin dengan membuat sayatan pada dinding uterus melalui dinding depan. Indikasi dari seksio sesarea meliputi: plasenta previa sentralis dan lateralis(posterior), panggul sempit, disproporsi sefalo pelvic, rupture uteri mengancam, partus lama (prolonged labor), partus tak maju (obstructed labor), distorsia serviks, preeklamsi dan hipertensi, malpresentasi janin, gawat janin, riwayat seksio sesarea.Patofisiologi dari kehamilan serotinus salah satunya yaitu gawat janin menunjukkan angka meningkat setelah kehamilan 42 minggu atau lebih, sebagian besar terjadi intrapartum. ${ }^{(1,2,10)}$ Indikasi dari seksio sesarea meliputi plasenta previa sentralis dan lateralis (posterior), panggul sempit, disproporsi sefalo pelvic, rupture uteri mengancam, partus lama (prolonged labor), partus tak maju (obstructed labor), distorsia serviks, pre-eklamsi dan hipertensi, malpresentasi janin, gawat janin, serta riwayat seksio sesarea. Komplikasi dari seksio sesarea ialah infeksi puerperal (nifas), perdarahan, luka kandung kemih, emboli paru, keluhan kandung kemih bila reperitonialisasi terlalu tinggi dan kemungkinan rupture uteri spontan pada kehamilan mendatang. ${ }^{(10)}$

Dari hasil penelitian bahwa sebagian besar ibu bersalin dengan kehamilan serotinus penanganannya dengan seksio sesarea.Dilihat dari indikasi, kontra indikasi serta komplikasinya kemungkinan sedikit angka keberhasilannya apabila dilakukan dengan metode menunggu serta induksi persalinan.Dimana gawat janin merupakan indikasi untuk 
terminasi kehamilan dengan seksio

sesarea.

\section{PENUTUP}

\section{A. Kesimpulan}

Berdasarkan penelitian sebagian besar penanganan kehamilan serotinus di RSUD Dr.H.Soewondo Kabupaten Kendal adalah dengan seksio sesarea yaitu sebanyak 69,4\%.

\section{B. Saran}

Bagi pelayanan kesehatan diharapkan tenaga kesehatan yang memberikan pelayanan kesehatan di RSUD Dr.H.Soewondo Kabupaten Kendal untuk dapat meningkatkan kualitas dan mutu pelayanan terutama tentang seksio sesarea dalam penanganan kehamilan serotinus agar kepuasan masyarakat dalam mendapatkan suatu pelayanan dapat terpenuhi dengan prosedur yang telah ditetapkan.

\section{DAFTAR PUSTAKA}

1. Prawiroharjo,Sarwono.llmu Kebidanan.Jakarta:PT Bina Pustaka; 2008.h.685-691.

2. Cunningham,F.Gary. Gant, Norman.F. Leveno,Kenneth.J. Gilstrap III,Larry C. Haunt,John C. Wenstrom, Katharine
D. Obstetri Williams.Jakarta:EGC;2005. h. 591, 810-811, 813-817.

3. Varney,Helen dkk.Buku Ajar Asuhan Kebidanan.Jakarta:EGC; 2006.

4. Tiara.Kehamilan Serotinus.30 Juni 2011 [diakses 25 Desember 2011].Didapat darihttp://tiara3arza.wordpress.com/2 011/06/30/kehamilanserotinus/.

5. Dinas Kesehatan Kabupaten Kendal.2011.

6. Prawiroharjo,Sarwono.Buku Acuan Nasional Pelayanan Kesehatan Maternal dan Neonatal.Jakarta:Yayasan Bina Pustaka;2008. h.89, 100, 305-307.

7. Manuaba, IBG. Manuaba, IA Chandranita. Manuaba, IBG Fajar. Pengantar Kuliah Obstetri.Jakarta:EGC;2007. h.450454, 800-802.

8. Sinclair, Constance.Buku Saku Kebidanan.Jakarta:EGC;2009.

9. Saifudin, Abdul Bari. Wiknjosastro, Gulardi Hanifa. Affandi, Biran. Waspodo Djoko. Buku Panduan Praktis Pelayanan Kesehatan Maternal dan Neonatal.Jakarta:Yayasan Bina Pustaka Sarwono Prawiroharjo;2006. h.P9-P14.

10. Mochtar, Rustam.Sinopsis Obstetri Jilid 2.Jakarta:EGC;1998. h. 55-56. 117-121.

11. Toksoplasmosis Dalam Kehamilan dan Induksi Persalinan.Pogi CabangSemarang Bag/SMT Obstetri\&Ginekologi FK.UNDIP RSUP Dr. Kariadi Semarang.2001.

12. Acradiat, Crisdiono M.Prosedur Tetap Obstetri dan Ginekologi.Jakarta:EGC;2004. h. 1521.

13. Manuaba Ida Bagus Gde. Operasi Kebidanan, Kandungan dan Keluarga Berencana Untuk Dokter Umum. Jakarta: EGC; 1999.h. 96-103.

14. Saryono, Ari Setiawan. Metodologi Penelitian Kebidanan DIII, DIV, S1 dan S2. Yogyakarta: Nuha Medika; 2011. h. 54, 100-101, 104,127

15. Notoatmodjo, Soekidjo. Metodologi Penelitian Kesehatan. Jakarta: Rineka Cipta;2010. h. 37, 105, 115, 130, 182 
16. Salamah, Umi. Suyanto. Riset Kebidanan. Jogjakarta: Mitra Cendikia Offset; 2008. h. 23

17. Arikunto, Suharsini. Prosedur Penelitian Suatu Pendekatan Praktik. Jakarta: Rineka Cipta; 2006. h. 131, 158

18. Machfoedz, Ircham.Statistika induktif bidang kesehatan, keperawatan, kebidanan, kedokteran bio statistika.Yogyakarta:Fitramaya;2008. h. 14

19. Hidayat, A. Aziz Alimul. Metode penelitian keperawatan dan teknik analisis data. Jakarta : salemba medika; 2007. h. 93-95 